\title{
Systemic Risk Index - Integrated Indicator of Financial Sustainability
}

\author{
By Oleg Ivanets ${ }^{1}$
}

\begin{abstract}
This paper contributes to the literature on financial sustainability in three major ways. First, it proposes a county-wide indicator of systemic risk that allows for including the risk factor into a broader macroeconomic analysis that was not done before. Second, it estimates systemic risk by financial assets, which is different from the common practice of estimating the risk by institutions. This approach allows for identifying risky assets that could lead to financial crises. By applying the model to the 1995-2016 data set, one can detect clear predictors of imminent crises. Finally, this paper estimates structural risk in the banking sector which is one of the major threats to the financial systems of developed countries.
\end{abstract}

Keywords: systemic risk, financial sustainability, financial stability, financial crises

\section{Introduction}

Sustainability of a financial system is one of the cornerstones of sustainable development. However, during the last two decades dominating trends in financial systems of developed countries have led to a significant increase of the public and private debt, but have not had an appreciable economic growth impact. Such level of debt and economic growth are by far not sustainable and pose a danger for future. Thus, identifying sources of these dangerous trends is the first step to turn the global financial system to a sustainable growth path and this paper contributes to this goal.

This paper is a part of larger research on the impact of the financial system on the economy in developed countries. The traditional view of the financial system as a capital transferring mechanism that supports economic growth gained lots of criticism following the Global Financial Crisis in 20081 . Following this criticism, a demand appeared for a new more realistic vision of the financial system. In particular, economists started paying larger attention to systemic risk as a negative impact of the financial system development. However, due to the lack of research on actual country-wide measures of systemic risk, there has been no complex analysis of the growth and risk impacts of the financial system on the economy. To address this gap, the present paper introduces the model of Systemic Risk Index (SRI) for conducting such analysis.

According to Kaufman and Scott (2003), "systemic risk is an established term and it refers to the risk or probability of breakdowns in an entire system, as opposed to breakdowns in individual parts or components, and is evidenced by co-movements (correlation) among most or all the parts" (p. 371). The common approach to estimate

${ }^{1}$ Stiglitz (2012) and Turner (2015), to name a few. 
systemic risk empirically is by allocating part of it to each financial institution on the market. To my knowledge, existing research focuses entirely on this type of systemic risk measures, mostly because that is how central banks assess and regulate the system-by institutions. There was a substantial amount of interest in the topic after the Global Financial Crisis in $2008^{2}$. One of the most important findings that are also supported by this paper is that significant financial crises like the one in 2008 are possible to predict. However, studying systemic risk by institutions has two main flaws that this paper addresses. First, due to the complex organizational structure of major financial institutions, using this method does not allow for capturing risks of particular financial assets. Second, due to immeasurable interdependence of the financial institutions, this approach does not offer any country-wide indicator of systemic risk. For these reasons, I have chosen an alternative way to assess systemic risk-by financial assets. In a way, I have eliminated financial institutions from the analysis, which allowed for estimating macroeconomic impacts of financial assets directly, but at the cost of ignoring institution-specific risks. Here it is important to understand that the systemic risk estimated by assets is not an alternative to the systemic risk estimated by institutions, but is a complimentary indicator. Although they overlap, each type of estimator covers some situations that the other does not. It is possible that there is a toxic (highly risky or overvalued) asset on the market, but its ownership is spread across the market in a way that there is no major institution that holds too much of the asset. In this case, systemic risk estimated by institution will be ineffective, while systemic risk by assets will capture $i^{3}$. On the other hand, it is often the case that management of a particular financial institution takes excessive risks or engages in fraudulent activities without having any toxic assets on the balance. In this case, only systemic risk by institutions is able to detect such an event prior to the crisis. Ideally, both indicators of systemic risk should be combined to obtain a complete picture of risks generated in the financial system, but this goes beyond the scope of this paper and presents a promising topic for future research. As this is the first paper to estimate systemic risk by financial assets, it is based not on the systemic risk literature, but on the literature dedicated to identifying and preventing financial crises. This literature provides insights into two major sources of financial crises: leverage and structural risks.

Leverage risk is the risk of not being able to repay the borrowed capital. The most notable idea, which was first postulated by Keynes (1936) and later expanded by Minsky (1992) and Reinhart and Rogoff (2009) is that financial crises are always associated with the excessive amount of debt and overly optimistic expectations about the future. Those two processes are inter-dependent: Optimistic expectations motivate people and firms to borrow more money, while borrowed money is usually spent on consumer goods, thereby driving GDP and stock market up and increasing the level of optimism until the

2 Acemoglu, Ozdaglar, Tahbaz-Salehi, and Alizera (2015); Acharya and Naqvi (2012); Acharya, Pedersen, Philippon, and Richardson (2017); Billio, Getmansky, Lo, and Pelizzon (2011); Bisias, Flood, Lo, and Valavanis (2012); Fostel and Geanakoplos (2012); Sabato (2010); Sherbina (2013); Wang and Wen (2012).

${ }^{3}$ Global Financial Crisis in 2008 is a good example of such an event. Despite the fact that some institutions were hit harder than others, almost the entire global financial system was involved in operations with toxic mortgage-backed securities (MBS). In this case, focusing on risk of the MBS as an asset class could have prevented the crisis. 
bubble is large enough to burst. Thus, leverage risk is one of the major sources of systemic risk.

Another important issue that has recently emerged is structural misbalance. The striking fact that currently only around $15 \%$ of the banking capital is transferred to business investments, while the remaining $85 \%$ serves other purposes was first brought up by Turner (2015) and further analyzed by Foroohar (2016). The idea of structural misbalance of the financial system that limits the economic growth was also analyzed by Stiglitz (2012), Stiglitz (2016), and Jacob and Mazzucato (2016). Structural risk is the risk of allocating capital to assets that are not productive or even harmful for the overall economic growth. This is the most important risk and the failure to identify it stands behind many major financial crises, including the Global Financial Crisis in 2008 and the Dot-com bubble in 2001. In this paper, I define "productive" capital allocations as operations that contribute to economic growth, in particular, through the increase in CAPEX, long-term corporate profits, or household income. On the other hand, "nonproductive" capital allocations contribute to asset price bubbles and the household debt. Any capital allocation operation is either predominantly productive, disruptive, or neutral in terms of its macroeconomic impact. "Predominantly" is the key word here as most of the financial operations are complex enough to have both productive and disruptive impacts; however, one is usually stronger than the other. For this reason, most operations could be identified as net productive, net disruptive, or neutral. This identification process is quite complex and also subjective due to the large amount of spill-over effects in the economy and different economic beliefs ${ }^{4}$. This is the reason why so little research on structural risk has been done in academic literature. However, the failure to address this problem is exactly what has led to financial crises in the past. Despite its complexity, this problem should be addressed and this paper is one of the few to do so.

The rest of the paper is structured as follows. Part 2 covers the methodology of the SRI. In Part 3, I describe the application of the developed model, whereas in Part 4 I draw conclusions and explicate the paper's contribution to the literature on financial stability.

\section{Methodology}

To create a single country-wide estimator of systemic risk, it is first necessary to separately estimate systemic risk of different types of financial assets. A typical developed financial system consists of the following types of assets: stocks, bonds, banking loans, private equity and venture capital funds (PE\&VC), and derivatives. Each type of assets has its own market or markets. Bonds market is divided into sovereign, municipal, corporate ${ }^{5}$ bonds, and mortgage-backed securities $\left(\mathrm{MBS}^{6}\right)$.

\footnotetext{
${ }^{4}$ Free market supporters believe that the market allocates assets effectively and any intervention will reduce efficiency.

${ }^{5}$ Corporate bonds could be divided into financial (banks) and non-financial. It would be nice to have this distinction because compared to the overall corporate sector of the economy, a typical bond market is disproportionally dominated by financial corporate bonds. However, the required data are often not available, so in this paper financial and non-financial bonds are counted together.
} 
This section introduces the theoretical model of systemic risk index and demonstrates the applied model with particular existing indicators.

\subsection{Theoretical Model}

The model captures major risks that affect systemic risk in accordance with the concept described above. Logically, the model has estimators of the leverage and structural risks, as well as a mechanism of integrating them into a single indicator.

Integration of various indicators of systemic risk into SRI is one of the key developments of this paper. The integration is based on the following goals:

$\checkmark$ Firm-level data incorporation: Ideally SRI should be estimated using firm-level data so that the spikes in SRI could be tracked down to particular assets. This is achieved by selecting indicators that are available at the firm level (except for the macroeconomic ones).

$\checkmark$ Dealing with missing data: SRI should be constructed and be meaningful even if a number of components are missing. This is achieved by standardizing all SRI components to the optimal baseline equal to 1 . This is achieved through a series of standardizing coefficients $\alpha \mathrm{j}$. Values of the coefficients are obtained by model calibration.

$\checkmark$ Simultaneous increase in structural and leverage risks on the same market has a negative synergistic effect that should be accounted for. This is achieved by using multiplication of risks instead of their summation.

$\checkmark$ Systemic risk indicators for different markets are integrated into Systemic Risk Index using the capital-weighted average. This accounts for the difference in the financial system structure of different countries.

Formal theoretical model for SRI:

$S R I=\sum_{\mathrm{j}=1}^{\mathrm{m}} \sum_{\mathrm{i}=1}^{\mathrm{n}} \frac{\mathrm{Ci}}{\mathrm{TC}} *(\alpha \mathrm{j} * \mathrm{SRi}) *(\alpha \mathrm{j} * \mathrm{LRi})$

where $i=1, n$ is the number of distinct markets of financial system; $j=1, m$ is the number of standardizing coefficients which is equal to the number of separate components of SRI; $\mathrm{Ci}$ is the capital of the particular market; TC is the total capital of the financial system that is analyzed; the sum of all $\mathrm{Ci}$ is equal to $\mathrm{TC}$, which makes $\mathrm{Ci} / \mathrm{TC}$ capital-weights; SRi is the Structural risk estimator for market "i"; LRi is the leverage risk estimator for market " $i$ "; $\alpha j$ is a set of standardizing coefficients.

Structural risk estimation is the most challenging part as there is practically no literature on this topic. As previously defined, structural risk is the risk of allocating capital in nonproductive assets. Thus, ideally structural risk estimator is a share of non-productive investments in total investments. Productivity of the investments is conventionally measured using the $\mathrm{NPV}^{7}$ concept. Combining it all together:

$\mathrm{SRi}=($ Capital allocated to projects with NPV of macroeconomic effects $<0) /$ total capital of the market " $i$ ".

Leverage risk estimation is much more common, so we have established the following indicators for it: debt-to-equity, debt-to-income, and debt-to-GDP that can be used

${ }^{6} \mathrm{MBS}$ are technically derivatives but are treated as bonds by most of the regulators, so the data on MBS are usually available as part of consolidated bonds data.

${ }^{7}$ Net Present Value 
depending on a particular market.

\subsection{Applied Model}

The conceptual framework for systemic risk is just the first step. The next challenge is how to practically estimate identified risks.

It is particularly challenging to estimate structural risk as there are no direct indicators capable to capture NPV of macroeconomic effects. To deal with this challenge, I use proxy indicators for stock market and banking. With regard to bonds markets, they are ignored in this analysis because there are no ready-made aggregate indicators available; however, they could be developed using firm-level data. This goes beyond the scope of this paper and requires further research.

Leverage risk estimation is straightforward.

Table 1. Financial System

\begin{tabular}{c|cccc}
\hline Risks/Assets $^{8}$ & Stocks & Sov, Muni, and MBS & Corporate Bonds & Banking \\
\hline Structural & P/E, EV/EBITDA, BB/NI & N/A & N/A & $(\mathrm{M}+\mathrm{C}) / \mathrm{B}$ \\
\hline Leverage & Debt-to-equity & Debt-to-GDP & Debt-to-equity & Debt-to-income \\
\hline
\end{tabular}

The main form of structural risk in the stock market is asset price bubbles. Excessive capital allocation to certain stocks, which is usually driven by overoptimistic expectations, boosts stocks' market capitalization significantly beyond their fundamental value and, as a result, the bubble is formed. At some point, the bubble bursts, which typically causes not only a stock market correction, but a significant economic crisis. The traditional way of analyzing how far the market value is from the fundamental value is ratio analysis, in particular the analysis of $\mathrm{P} / \mathrm{E}$ and $\mathrm{EV} / \mathrm{EBITDA}$. Their deviations from historical averages usually indicate the growth phase of an economic cycle that is commonly followed by a bubble formation. In addition to these traditional indicators of structural risk, there is one relatively new indicator: buybacks-to-net income (BB/NI). Despite being a relatively new phenomenon, ${ }^{9}$ buybacks quickly became one of the most dangerous trends in the stock market ${ }^{10}$, so one has to include them when assessing the structural risk of the stock market.

As a proxy for structural risk in banking, a share of relatively non-productive loans in total loans is used. I consider only three types of loans. Mortgage ${ }^{11}(\mathrm{M})$ and consumer (C) loans are considered to be not-productive, while business (B) loans are productive. Thus, the ratio of $(\mathrm{M}+\mathrm{C}) / \mathrm{B}$ indicates structural risk for banking loans.

Formal applied model for SRI:

$S R I=\frac{\text { Cst }}{\mathrm{TC}} \mathrm{SRIst}+\frac{\mathrm{Cb}}{\mathrm{TC}} * \mathrm{SRIb}+\frac{\mathrm{Cl}}{\mathrm{TC}} * \mathrm{SRIl}$,

\footnotetext{
${ }^{8}$ In the applied model, PE\&VC and derivatives are not covered due to the lack of data. Both markets have, however, a significant contribution to the overall systemic risk, which makes this an important topic for further research.

9 The available data are from 2005, so we ignore buybacks from the prior period.

${ }^{10}$ Lazonick (2014).

11 Some economists consider mortgage loans productive as they are supposed to stimulate construction industry; in reality, they stimulate an increase in housing prices. More information on this topic is available at http://olegivanets.wordpress.com.
} 
where Cst is the capital of stock market, $\mathrm{Cb}$ is the capital of bonds market, $\mathrm{Cl}$ is the capital allocated to banking loans, and $\mathrm{TC}=\mathrm{Cst}+\mathrm{Cb}+\mathrm{Cl}$.

SRIst $=\frac{\left[\frac{\left(\frac{\mathrm{EV}}{\mathrm{EBITDA}}\right)}{\alpha 1}+\frac{\overline{\mathrm{E}}}{\alpha 2}\right]}{2} * \frac{1+\left(\frac{\mathrm{BB}}{\mathrm{NI}}\right)}{\alpha 3} * \frac{(\text { Debt/Equity) }}{\alpha 4}$

All indicators are for publicly traded companies.

$S R I b=\frac{\mathrm{Csb}}{\mathrm{Cb}} * \frac{\frac{\mathrm{Csb}}{\mathrm{GDP}}}{\alpha 5}+\frac{\mathrm{Cmb}}{\mathrm{Cb}} * \frac{\frac{\mathrm{Cmb}}{\mathrm{GDP}}}{\alpha 6}+\frac{\mathrm{Cmbs}}{\mathrm{Cb}} * \frac{\frac{\mathrm{Cmbs}}{\mathrm{GDP}}}{\alpha 7}+\frac{\mathrm{Ccb}}{\mathrm{Cb}} * \frac{\frac{\text { Debt }}{\mathrm{Equity}}}{\alpha 4}$

where Csb is sovereign bonds outstanding, $\mathrm{Cmb}$ is municipal bonds outstanding, $\mathrm{Cmbs}$ is MBS outstanding, $\mathrm{Ccb}$ is corporate bonds outstanding, and $\mathrm{Cb}=$ $\mathrm{Csb}+\mathrm{Cmb}+\mathrm{Cmbs}+\mathrm{Ccb}$.

SRIl $=\frac{(\mathrm{M}+\mathrm{C})}{\alpha 8 * \mathrm{~B}} * \frac{(\mathrm{Cl})}{\alpha 9 * \mathrm{I}}$

where $\mathrm{I}$ is the total household income and $\mathrm{Cl}=\mathrm{B}+\mathrm{M}+\mathrm{C}$.

$\alpha 1-\alpha 9$ is a set of standardizing coefficients aimed at balancing components of SRI to baseline of 1 .

\section{Application}

\subsection{Data}

In this paper, I explore the financial systems of seven countries ${ }^{12}$ by analyzing the following financial markets: stock, bonds (divided into sovereign, municipal, corporate, and MBS) and banking.

All economic data have been taken from national government statistics institutions, central banks, and international economic institutions such as IMF and OECD. If a data set is missing for a particular country or time period, the model is calculated without those indicators. Few missing data points are filled with interpolated estimators. GDP and income for 2016 are based on the latest IMF estimations. Stock market data as well as debt/equity indicator are used only for companies added to major stock indices of each country ${ }^{13}$ and are obtained from Bloomberg ${ }^{14}$. As other data are not available, debt/equity indicator for bonds market is used only for publicly traded companies. Stock buybacks data were provided by Factset and are available only for the US.

Table 2. Standardizing Coefficients

\begin{tabular}{clcl}
\hline Coefficient & Name & Value & Value Justification \\
\hline $\boldsymbol{\alpha} \mathbf{1}$ & EV/EBITDA & 8.9 & Maximum of the minimal values ${ }^{15}$ for 1995-2016 \\
$\boldsymbol{\alpha} \mathbf{2}$ & $\mathrm{P} / \mathrm{E}$ & 11.1 & Maximum of the minimal values for 1995-2016 \\
$\boldsymbol{\alpha} \mathbf{3}$ & 1+BB/NI & 1.4 & Minimal value for 2005-2016 (US only) \\
$\boldsymbol{\alpha} \mathbf{4}$ & Debt/Equity & 1.4 & Average of the minimal values for 1995-2016 \\
$\boldsymbol{\alpha} \mathbf{5}$ & Gov.Debt/GDP & 0.6 & Average for 1995-2007 \\
$\boldsymbol{\alpha} \mathbf{6}$ & Muni.Debt/GDP & $\mathbf{6 . 4}$ & US average for stable period of 1995-200316 \\
\hline
\end{tabular}

12 US, UK, Germany, France, Italy, Australia, and Canada. The countries were selected based on the level of development and data availability.

13 Used indices are S\&P 500, FTSE 100, CAC 40, DAX, FTSE MIB, S\&P/ASX 200, and S\&P/TSX.

14 For details about data, please contact the author.

15 Across all countries unless otherwise stated. 


\begin{tabular}{clcl}
\hline $\boldsymbol{7} 7$ & MBS/GDP & 2 & US average for stable period of 1995-1998 \\
$\alpha \mathbf{8}$ & $(\mathrm{M}+\mathrm{C}) / \mathrm{B}$ & 1.2 & Average across all countries for 1995-2016 \\
$\boldsymbol{\alpha} \mathbf{9}$ & Loans/Income & 0.9 & Average across all countries for 1995-1999 \\
\hline
\end{tabular}

Values of standardizing coefficients are obtained using the model calibration based on various criteria. All of the values correspond to an idea of "good times value."

\subsection{Results}

Graph 1 presents aggregated results for seven selected countries. The first striking result is that the US financial system has a significantly higher risk compared to the financial systems of other countries. In addition, the US SRI, which had been building up since 2000 and peaked in 2008, makes the Global Financial Crisis predictable. Another problem with the US is that after the crisis systemic risk did not return to the baseline level, but instead was reallocated from the private financial sector to the government. Another critical finding is that systemic risk has started growing again in recent years while being two times as high as the baseline. With regard to other countries, we can see that systemic risk has increased significantly for all countries except for the eurozone ones. Due to austerity policies and some fundamental problems with Euro that are not captured by the model, the eurozone countries managed to remain relatively stable or even improve their systemic risk. Surprisingly, Australia proved to have the worst dynamic of systemic risk, which can be attributed mostly to an extensive mortgage loans build-up.

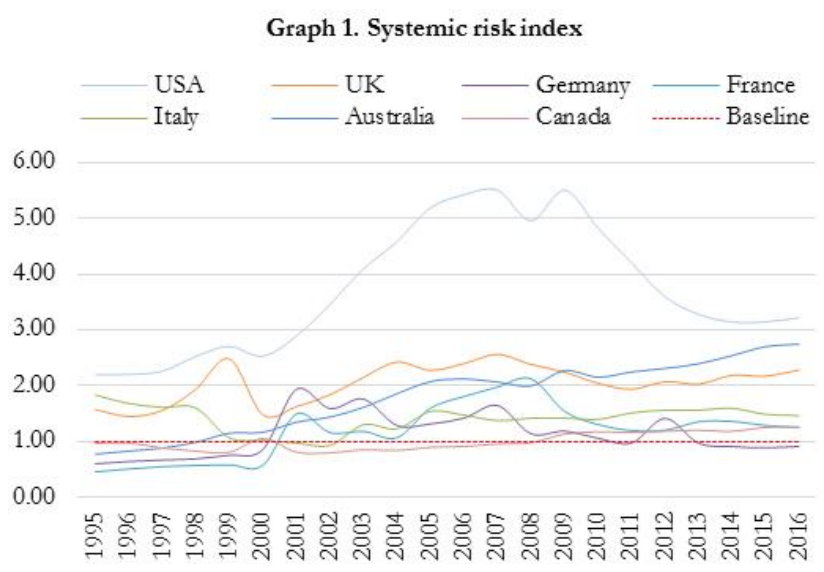

Due to standardization of all components of SRI, it is relatively easy to track the particular financial assets that cause extreme values of the overall SRI. Table 3 below provides a summary of the main SRI drivers per country.

${ }_{16}$ Municipal bonds and MBS markets are developed only in US. In other countries they are not so popular, so makes sense to use US data for the baseline. 
Table 3. Key SRI Drivers

\begin{tabular}{|c|c|c|}
\hline Country & Risk & Description \\
\hline \multirow[t]{3}{*}{ US } & $\begin{array}{l}\text { Mortgage } \\
\text { loans }\end{array}$ & $\begin{array}{l}\text { Mortgage loans, in particular those that are provided by federal agencies, } \\
\text { created the main structural misbalance in the US economy, led to the } \\
\text { Global Financial Crisis, and continue to create a significant threat to the } \\
\text { US economy. The current US banking systemic risk is } 4.9 \text { (down from } \\
9.4 \text { in 2010), which is still extremely high. }\end{array}$ \\
\hline & $\begin{array}{l}\text { Sovereign } \\
\text { bonds }\end{array}$ & Sovereign bonds risks spiked significantly after 2008. \\
\hline & $\begin{array}{l}\text { Stock } \\
\text { market }\end{array}$ & $\begin{array}{l}\text { Stock market is reaching dangerous levels of stock valuations that are } \\
\text { usually associated with asset price bubbles. }\end{array}$ \\
\hline UK & $\begin{array}{l}\text { Mortgage } \\
\text { loans }\end{array}$ & $\begin{array}{l}\text { Similar to the US, the UK mortgage loans pose a significant threat to the } \\
\text { financial stability }\end{array}$ \\
\hline Germany & $\begin{array}{l}\text { Too low } \\
\text { risk }\end{array}$ & $\begin{array}{l}\text { Germany has SRI that is significantly below the baseline. While in } \\
\text { general it is a good outcome, due to complex EU issues Germany's } \\
\text { particularly low risk poses a problem for the balanced development of } \\
\text { the EU } \mathrm{EU}^{17} \text {. }\end{array}$ \\
\hline France & $\begin{array}{l}\text { No major } \\
\text { risks }\end{array}$ & $\begin{array}{l}\text { While France has the most balanced financial system, it is affected by } \\
\text { complex eurozone issues that are not captured by SRI. }\end{array}$ \\
\hline Italy & $\begin{array}{l}\text { Sovereign } \\
\text { bonds }\end{array}$ & $\begin{array}{l}\text { Italy is naturally similar to France; however, it has higher sovereign } \\
\text { bonds risks. }\end{array}$ \\
\hline Australia & $\begin{array}{l}\text { Mortgage } \\
\text { loans }\end{array}$ & $\begin{array}{l}\text { Australia has the worst dynamic of SRI due to an extremely extensive } \\
\text { mortgage loans growth, which might lead to a housing crisis. }\end{array}$ \\
\hline Canada & $\begin{array}{l}\text { Stock } \\
\text { market }\end{array}$ & $\begin{array}{l}\text { Following the US stock market trends, stock valuations in Canada are } \\
\text { now reaching dangerous levels. }\end{array}$ \\
\hline
\end{tabular}

\section{Conclusion}

Systemic Risk Index proposed in this paper is the first county-wide indicator of financial sustainability that can be used in the broader macroeconomic analysis. Despite the gaps in some data sets, the application of SRI allowed for identifying multiple issues in the financial systems of select countries. The largest of those issues is the structural misbalance of bank loans in countries other than those in the eurozone. This misbalance is driven by a disproportionally large amount of mortgage loans that lead to a surge in housing prices, but do not have an impact on the household income, thereby making the overall financial system unsustainable. Taking into account that the majority of the loans in the US are provided by the federal government agencies, this problem is particularly serious because such policy interventions are not affected by the market dynamics.

Accounting for the systemic risk is an essential part of building a sustainable financial system. This paper is the initial attempt to establish a new analytical framework, in which the decisions made by investors and regulators take into consideration the systemic risk of the financial system. 


\section{References}

Acemoglu, D., Ozdaglar, A., \& Tahbaz-Salehi, A. (2015). Systemic risk and stability in financial networks. The American Economic Review, 105(2), 564-608.

Acharya, V. V., Pedersen, L. H., Philippon, T., \& Richardson, M. (2017). Measuring systemic risk. Review of Financial Studies, 30(1), 2-47.

Acharya, V., \& Naqvi, H. (2012). The seeds of a crisis: A theory of bank liquidity and risk taking over the business cycle. Journal of Financial Economics, 106(2), 349-366.

Billio, M., Getmansky, M., Lo, A. W., \& Pelizzon, L. (2012). Econometric measures of connectedness and systemic risk in the finance and insurance sectors. Journal of Financial Economics, 104(3), 535-559.

Bisias, D., Flood, M., Lo, A. W., \& Valavanis, S. (2012). A survey of systemic risk analytics. Annual Review of Financial Economics, 4(1), 255-296.

Foroohar, R. (2016). Makers and takers: The rise of finance and the fall of American business. New York, NY: Crown Business.

Fostel, A., \& Geanakoplos, J. (2012). Tranching, CDS, and asset prices: How financial innovation can cause bubbles and crashes. American Economic Journal: Macroeconomics, 4(1), 190-225.

Jacobs, M., \& Mazzucato, M. (Eds.). (2016). Retbinking capitalism: Economics and policy for sustainable and inclusive growth. Chichester, UK: John Wiley \& Sons.

Kaufman, G. G., \& Scott, K. E. (2003). What is systemic risk, and do bank regulators retard or contribute to it? The Independent Review, 7(3), 371-391.

Keynes, J. M. (1936). General theory of employment, interest and money. London, UK: Palgrave Macmillan.

Lazonick, W. (2014). Profits without prosperity. Harvard Business Review, 92(9), 46-55.

Minsky, H. P. (1992). The financial instability hypothesis. Working paper 74. New York, NY: The Jerome Levy Economics Institute of Bard College.

Reinhart, C. M., \& Rogoff, K. S. (2009). This time is different: Eight centuries of financial folly. Princeton, NJ: Princeton University Press.

Sabato, G. (2010). Financial crisis: Where did risk management fail? International Review of Applied Financial Issues and Economics, 2(2), 315-327.

Scherbina, A. (2013). Asset price bubbles: A selective survey. IMF Working Paper WP/13/45.

Stiglitz, J. E. (2012). The price of inequality: How today's divided society endangers our future. New York, NY: WW Norton \& Company.

Stiglitz, J. E. (2016). How to restore equitable and sustainable economic growth in the United States. The American Economic Review, 106(5), 43-47.

Turner, A. (2015). Between debt and the devil: Money, credit, and fixing global finance. Princeton, NJ: Princeton University Press.

Varoufakis, Y. (2016). And the weak suffer what they must?: Europe's crisis and America's economic future. New York, NY: Nation Books.

Wang, P., \& Wen, Y. (2012). Speculative bubbles and financial crises. American Economic Journal: Macroeconomics, 4(3), 184-221. 